
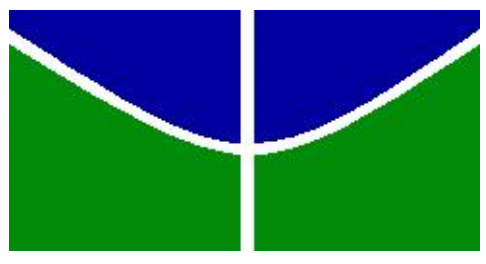

UNIVERSIDADE DE BRASÍLIA

Faculdade de Educação - UAB/UNB MECISECAD

Curso de Especialização em Educação na

Diversidade e Cidadania, com Ênfase em EJA

FATIMA CAMPOS

PAULO HENRIQUE BALDUINO SILVA

SILVIA HELENA DA SILVA CABRAL CARVALHO

TANIA REGINA CRUZ SANTOS

\title{
EDUCAÇÃO SEXUAL NA EJA
}

BRASÍLIA, DF

Julho/2010 
UNIVERSIDADE DE BRASÍLIA

Faculdade de Educação - UAB/UNB MEC/SECAD

Curso de Especialização em Educação na

Diversidade e Cidadania, com Ênfase em EJA

FATIMA CAMPOS

PAULO HENRIQUE BALDUINO SILVA

SILVIA HELENA DA SILVA CABRAL CARVALHO

TANIA REGINA CRUZ SANTOS

\section{EDUCAÇÃO SEXUAL NA EJA}

CARMENÍSIA JACOBINA AIRES

ALEXANDRA PEREIRA DA SILVA

PROJETO DE INTERVENÇÃO LOCAL

BRASÍLIA, DF Julho/2010 
UNIVERSIDADE DE BRASÍLIA

Faculdade de Educação - UAB/UNB MEC/SECAD

Curso de Especialização em Educação na

Diversidade e Cidadania, com Ênfase em EJA

FATIMA CAMPOS

PAULO HENRIQUE BALDUINO SILVA

SILVIA HELENA DA SILVA CABRAL CARVALHO

TANIA REGINA CRUZ SANTOS

\section{EDUCAÇÃO SEXUAL NA EJA}

Trabalho de Conclusão de Curso de Especialização em Educação na Diversidade e Cidadania, com Ênfase em EJA, como parte dos requisitos necessários para obtenção do grau de Especialista na Educação de Jovens e Adultos.

\begin{tabular}{c}
\hline $\begin{array}{c}\text { Carmenísia Jacobina Aires } \\
\text { Professora orientadora }\end{array}$ \\
\hline $\begin{array}{c}\text { Alexandra Pereira da Silva } \\
\text { Tutora orientadora }\end{array}$ \\
\hline
\end{tabular}

Elaine Filomena Cárcere Vítor

Avaliadora Externa

BRASÍLIA, DF julho, 2010 
Dedicamos este trabalho primeiramente a Deus que nos concedeu a oportunidade de concluir mais uma etapa em nossas vidas. A Faculdade de Educação que não mediu esforços para proporcionar mais uma oportunidade de crescimento. Aos amigos e companheiros de estudo. As Professoras Alexandra Pereira da Silva e Carmenísia Jacobina Aires pelo incentivo, orientação e contribuição dada no decorrer do curso que foi de grande importância para a conclusão deste trabalho. 


\section{AGRADECIMENTOS}

No começo deste caminhar se faz jus ao ser humano acreditar em seus objetivos. É claro que diante das adversidades do dia-a-dia traçamos e retraçamos novos conceitos e nos propomos a novos paradigmas. Nesse momento a conclusão é uma vitória que temos que agradecer sempre ao Pai Celestial, pois se esquecemos das dificuldades e se chegamos até aqui é porque tivemos saúde, força, garra, sabedoria para o enfrentamento que o curso nos colocava. Trabalhar sem cobranças, sem hora para fazer os exercícios propostos, mas comum dead line sério e o incansável esforço da coordenação do curso em fazer com que a cada um chegasse até ao final com muito louvor.

Agradecemos as pessoas que direta ou indiretamente, ajudaram na elaboração deste trabalho, aos alunos da Educação de Jovens e Adultos que participaram deste projeto, à coordenação da Escola Nova Friburgo, e ao corpo docente do curso de especialização, pelos ensinamentos, à nossa orientadora Carmenísia Jacobina Aires pelo apoio e realização deste trabalho. 
“... É preciso viver relativamente bem à sexualidade. Não podemos assumir com êxito pelo menos relativo, a paternidade, a maternidade, o professorado, a política, sem que estejamos mais ou menos em paz com a Sexualidade." (Paulo Freire) 


\section{LISTA DE SIGLAS}

AIDS Síndrome de Doença Imunológica Adquirida.

DST Doenças Sexualmente Transmissíveis.

EJA Educação de Jovens e Adultos.

HIV Vírus da Imunodeficiência Humana.

SESC Serviço Social do Comércio.

OMS Organização Mundial de Saúde.

PDE Plano de Desenvolvimento da Escola.

PME Plano de Melhoramentos da Escola.

PPP Plano Político Pedagógico.

SUS Sistema Único de Saúde.

PCN Parâmetros Curriculares Nacionais. 


\section{RESUMO}

Atualmente, a escola tem sido apontada como um importante espaço para veicular informação sobre formas de evitar a gravidez indesejada e de se proteger de doenças sexualmente transmissíveis (DST) e AIDS. Nos últimos anos, a sexualidade adolescente adquiriu uma dimensão de problema social. Mais que um problema moral, ela é vista como um problema de saúde pública, e a escola desponta como um local privilegiado de implementação de políticas públicas que promovam a saúde de crianças e adolescentes. Exemplo da intenção de inserir este assunto no âmbito escolar é sua transformação em um elemento curricular: nos Parâmetros Curriculares Nacionais (PCNs), a orientação sexual é um tema transversal. De acordo com os Parâmetros, os temas transversais abordam problemas fundamentais e urgentes da vida social, sendo que o tema educação sexual foi criado em virtude do crescimento de casos de gravidez indesejada entre adolescentes e de riscos da contaminação pelo HIV. Cabe, portanto, à escola e não mais apenas à família, desenvolver uma ação crítica, reflexiva e educativa que promova a saúde das crianças e dos adolescentes (BRASIL, 1998). Assim, a escola, passa a ser pensada como um dispositivo político privilegiado de intervenção, buscando expandir o impacto sobre a população através do controle da sexualidade adolescente. O Projeto de Intervenção Local é Educação Sexual na EJA voltado para a promoção da cidadania saudável propondo a redução da vulnerabilidade da comunidade escolar em relação à gravidez e DST/ AIDS.

Palavras-chave: Sexualidade, DST/AIDS, Jovens e Adultos. 


\section{SUMÁRIO}

1- Dados de identificação dos proponentes.............................................................

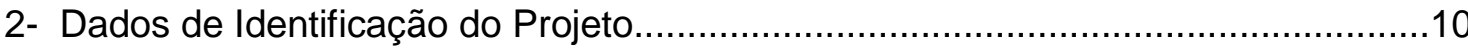

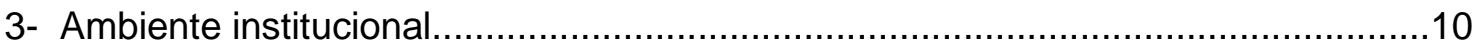

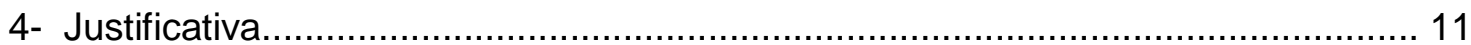

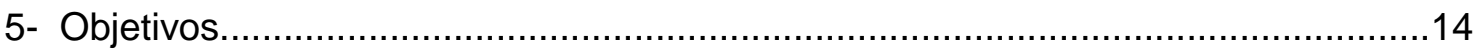

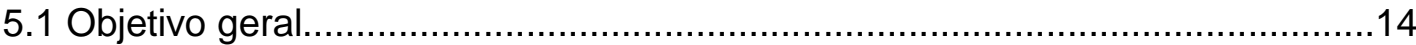

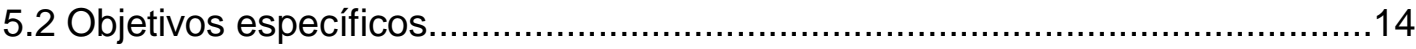

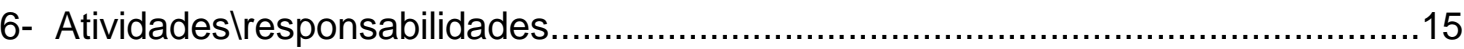

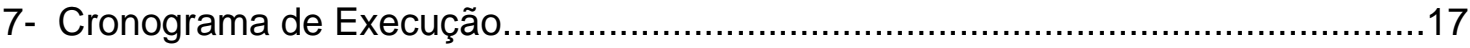

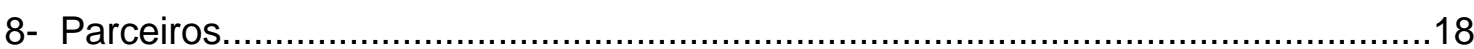

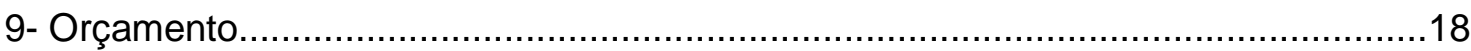

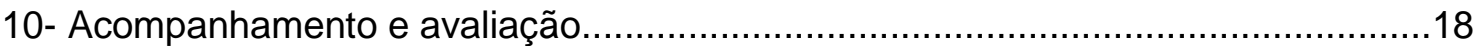

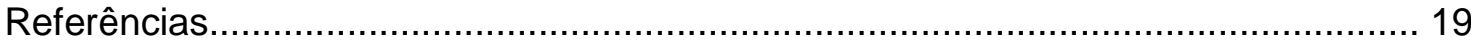




\section{DADOS DE IDENTIFICAÇÃO DOS PROPONENTES}

Fátima Campos - professoracampos@hotmail.com - (061) 99054560

Silvia Helena - silviac@sescdf.com.br - (061) 91424464

Tânia Regina Cruz Santos - taniacz@hotmail.com - (061) 92952666

Paulo Henrique Balduino Silva - phbalduino@hotmail.com - (061) 84553113

\section{DADOS DE IDENTIFICAÇÃO DO PROJETO}

\subsection{TÍTULO}

\section{EDUCAÇÃO SEXUAL NA EJA}

\section{2. ÁREA DE ABRANGÊNCIA}

Projeto de Intervenção local.

\subsection{INSTITUIÇÃO}

Colégio Municipal Nova Friburgo. Endereço: Área Especial Quadra 24 s/n Parque Nova Friburgo Etapa "B" Instituição subordinada à Secretaria de Educação e Desporto e Lazer de Cidade Ocidental.

\subsection{PÚBLICO ALVO}

Estudantes da EJA do $1^{\circ}$ e $2^{\circ}$ segmento. São jovens e adultos trabalhadores que apresentam carência de informações a respeito de uma orientação sexual mais próxima a sua realidade e por terem pouco acesso à leitura informativa sobre o assunto abordado, ou seja, o projeto é destinado a um público que traz consigo uma deficiência muito grande em termos de informações e orientação adequada de como se prevenir a respeito das DST's e na busca de uma melhor qualidade de vida.

\subsection{PERÍODO DE EXECUÇÃO}

Será um total de 11 meses. No período compreendido entre os meses de fevereiro a dezembro de 2011.

\section{AMBIENTE INSTITUCIONAL}

A Escola Municipal Nova Friburgo, foi fundada em 1982 como uma Escola Municipal de $1^{\circ} \mathrm{Grau}$ Multigraduada. Na época, uma professora lecionava para as quatro séries iniciais em uma mesma sala de aula. Existiam apenas 23 alunos e era considerada escola rural do Município de Luziânia, subordinada à Secretaria Municipal de Educação e Cultura.Na década de 90, a escola passou por uma série de reformas, 
pois o bairro foi crescendo e a demanda dos alunos foi aumentando, com isso fez-se necessário adequar à escola a uma nova realidade, passou então a se chamar Escola Municipal Nova Friburgo e oferecia Ensino Fundamental.

Em 1993, a escola implantou no Município a proposta de Alfabetização de Jovens e Adultos, o que mais tarde veio a se tornar a modalidade de Ensino EJA Educação de Jovens e Adultos do $1^{\circ}$ e $2^{\circ}$ segmentos. Hoje a Escola Municipal apresenta uma estrutura administrativa com indicações políticas para o exercício de Diretor e Secretário. A estrutura pedagógica da instituição escolar está definida da seguinte forma; coordenadores pedagógicos e coordenadores de turno para a Educação Básica (diurno); coordenador pedagógico e coordenador de turno para a Modalidade EJA (noturno). O corpo docente da escola é composto por 78 professores legalmente habilitados lotados nesta unidade de ensino e integram o quadro docente do Município de Cidade Ocidental-GO.

Em relação ao corpo discente podemos dizer que há aproximadamente 900 alunos regularmente matriculados, sendo divididos entre o Ensino Regular e a modalidade de EJA. O Conselho de classe é participativo de acordo com a Lei 194/2005 da Lei de Diretrizes e Bases da Educação. A escola tem com bases pedagógicas o PPP (Plano Político Pedagógico), PDE (Plano de Desenvolvimento da Escola), PME (Plano de Melhoramento da Escola) e também atua com projetos como "Convivência na Escola", "Diversidade Cultural" e "Combate à Discriminação".

No que diz respeito à estrutura física há quinze salas de aulas de aula, um laboratório de informática, uma secretária com um banheiro, uma sala da diretoria e uma sala para a coordenação, uma biblioteca com banheiro, uma cantina, uma sala de professores com banheiro, seis banheiros masculinos e femininos para os alunos e dois depósitos. A escola tem por finalidade um Ensino Público de qualidade com a participação da família e da comunidade.

\section{JUSTIFICATIVA}

O tema escolhido, para a elaboração deste projeto, vem ao encontro das necessidades de jovens e adultos no que diz respeito à orientação sobre a Educação Sexual e o Incentivo à leitura. Nesse sentido, entendemos a Educação como uma prática social que preconiza não só a mudança de hábitos, práticas e atitudes, a transmissão e apreensão de conhecimentos, mas principalmente, a mudança gradual na forma de pensar, sentir e agir através da seleção e utilização de métodos pedagógicos participativos e problematizados. A educação sexual na escola sempre foi objeto de polêmica em nossa tradição educacional. A escola brasileira pública e 
privada, sempre manteve este tema distante de seus procedimentos, do currículo e responsabilidades institucionais. (NUNES, 2000). Segundo Paulo Freire:

\footnotetext{
"A transformação social era entendida de forma simplista, fazendo-se com a mudança, primeiro das consciências,como se fosse à consciência de fato,a transformadora do real, agora a transformação social é percebida como processo histórico em que subjetividade e objetividade se prendem dialeticamente." (PAULO FREIRE, A importância do ato de ler, p.30).
}

Educar e aprender torna-se um processo contínuo de indagação, reflexão, questionamento e principalmente, de construção coletiva, articulada e compartilhada. $\mathrm{O}$ educador e o educando tornam-se sujeitos e atores do processo educativo, que estimula continuamente a organização de ações coletivas e solidárias, incentivando e valorizando o diálogo, a criatividade e a criticidade, objetivando a busca de soluções para as questões que afetam as comunidades, em prol da melhoria do educando, para que, busquem uma valorização dos mesmos na sociedade. Educar constitui o ato de buscar o fortalecimento da autonomia do educando e não sua dependência, estimulando-o a tomar decisões e buscando o controle de sua própria vida. Assim, indivíduos, famílias e coletividade, sensibilizados, informados e fortalecidos para o enfrentamento das questões da gravidez e DST IAIDS, obtêm condições para identificar, conhecer, analisar e avaliar os motivos de ocorrência dos problemas que afetam à saúde. E para que tomem consciência dessa realidade se faz necessária uma leitura dialógica de mundo onde se tornam sujeitos ativos e participantes das decisões para modificá-la, reconhecendo seu potencial transformador e criador, colaborando de forma efetiva na solução e /ou encaminhamento dos problemas. Para Sampaio (1995) a sexualidade deve ser orientada de forma a preparar o individuo para a vida, porém para educar é preciso que o educador esteja preparado para tal tarefa.

Busca-se considerar a sexualidade como algo inerente à vida e à saúde, que se expressa desde cedo no ser humano. Engloba o papel do homem e da mulher, o respeito por si e os estereótipos atribuídos e vivenciados em seus relacionamentos, o avanço da AIDS e da gravidez indesejada na adolescência, entre outros que são problemas atuais e preocupantes. Todos esses fatores denotam uma necessidade cada vez maior da inclusão da temática sexual no currículo escolar. 
A falta de acesso a informações sobre orientação sexual deixa o educando mais vulnerável a problemas como DST's e a gravidez precoce. Diante deste quadro é eminente a necessidade de oferecer uma leitura mais objetiva que enfoque o problema e desperte no educando da EJA uma visão mais crítica e fundamentada na construção de um saber próprio acrescido de conhecimento intervencionista. De acordo com Paulo Freire: “... O problema que se coloca não é a leitura da palavra, mas o de uma leitura mais rigorosa do mundo, que sempre precede a leitura da palavra." (Paulo Freire, A importância do Ato de Ler, p.31). Cabe aos educadores da EJA um comprometimento maior a respeito da importância e necessidade que tem o ato da leitura como instrumento de informação eficaz que torne o educando da EJA um ator importante no processo de transformação social.

A Escola pode assumir um papel fundamental nesse processo. O Projeto "Educação Sexual na EJA" surge não só como uma estratégia para promover indivíduos e coletividade de informações, pois reconhece que a informação não é suficiente para favorecer mudanças, mas uma chave, dentro do processo educativo, para compartilhar conhecimentos e práticas que podem contribuir para a conquista de melhores condições de vida. Reconhecemos que a informação de qualidade, difundida no momento oportuno, com utilização de uma linguagem clara e objetiva, é um poderoso instrumento de promoção da educação. O processo de comunicação deve ser ético, transparente, atento aos valores, opiniões, tradições, culturais e crenças das comunidades, respeitando, considerando e reconhecendo as diferenças, baseando-se na apresentação e avaliação de informações educativas, interessantes, atrativas e compreensíveis. Seguindo as idéias de Vygotsky (VYGOTSKY, Uma perspectiva histórico-cultural da educação, 2004.p.41)

\footnotetext{
"As características tipicamente humanas não estão presentes desde o nascimento do indivíduo, nem são mero resultado das pressões do meio externo. Elas resultam da interação dialética do homem e seu meio cultural. Ao mesmo tempo em que o ser humano transforma o seu meio para atender suas necessidades básicas, transforma-se a si mesmo."
}

É por meio do diálogo, e da interatividade social que o indivíduo busca as soluções para os seus problemas básicos construindo seus saberes externos associados aos seus internos já adquiridos.

A escola é um órgão que tem vida e vida é um desafio contínuo. Abraçando educação sexual estará abraçando o "viver". O viver é dinâmico. Há sempre uma 
busca, seja intelectualmente, seja de crescimento e felicidade. Todos têm o direito, o dever de buscar felicidade. A educação sexual sadia contribuirá para isso. O tema da sexualidade está na "ordem do dia" da escola.

Presente em diversos espaços escolares ultrapassa fronteiras disciplinares e de gênero, permeia conversas entre meninos e meninas e é assunto a ser abordado na sala de aula pelos diferentes especialistas da escola; é tema de capítulos de livros didáticos, bem como de músicas, danças e brincadeiras que animam recreios e festas (ALTMANN, 2001).

Outro desafio da educação sexual na escola é o de orientar os alunos para a liberdade. O educador sexual não poderá permitir tudo nem reprimir nada. Isso é difícil. Terá de informar, passar conhecimentos e simultaneamente dar condições para que adquiram um sistema de valores muito pessoal.

Os jovens evoluem de forma descompassada. Em certas áreas desenvolvem-se rapidamente, com desacertos físicos, psíquicos e sociais. Em outras, seguirão lentamente. O ser humano está sempre em evolução, transformando-se e adquirindo novos costumes. $E$ a maioria dos novos conhecimentos é adquirida na escola, seja através dos conteúdos formais ou da convivência com a comunidade escolar que promove um conhecimento informal, porém muitas vezes bem representativo para aquele que o recebe.

Dentro deste contexto, este PIL oferece uma contribuição para a escola com o objetivo de promover a cidadania e transformar o quadro em questão. É um projeto voltado para a promoção de uma sociedade saudável e a redução da vulnerabilidade da comunidade escolar em relação à Gravidez e as DST / AIDS.

\section{OBJETIVOS}

\subsection{Objetivo Geral}

Desenvolver na ESCOLA, um projeto de Educação Sexual, por meio do incentivo à leitura e uso do material didático pedagógico que propicie condições para o desenvolvimento dos alunos e do senso de responsabilidade sobre a saúde individual e coletiva, promovendo assim, a redução da gravidez precoce e das DST / AIDS.

\subsection{Objetivos específicos}

- Proporcionar aos alunos de EJA oportunidade para esclarecer dúvidas e expressar opiniões, através de oficinas. 
- Realizar debates que funcionem como multiplicadores dos conhecimentos adquiridos em seu ambiente de vida (escola, trabalho, família).

- Avaliar a opinião dos professores, das coordenações das escolas e dos alunos de EJA a respeito do desempenho do projeto e atividades realizadas.

- Trocar experiências com outros educadores para ampliar as possibilidades de operacionalização de propostas;

- Desenvolver através de dinâmicas uma reflexão individual para ampliar a compreensão do processo de transformação corporal, psicológica e social.

\section{ATIVIDADES/RESPONSABILIDADES}

1 Palestras

1.1 Doenças Sexualmente Transmissíveis - DST;

1.2 AIDS;

1.3 Gravidez na Adolescência;

1.4 Planejamento Familiar;

1.5 Métodos Contraceptivos.

1.6 Aplicação do material didático.

1.7 As oficinas acontecerão após as palestras com o objetivo de incentivar educandos a ter uma visão mais ampla e crítica no que se refere à educação sexual.

\section{Objetivos}

Adquirir conhecimentos sobre as doenças sexualmente transmissíveis e a respeito da importância da busca de tratamento médico; aprofundar conhecimentos para a realização do trabalho educativo voltado para a prevenção e tratamento precoce das doenças sexualmente transmissíveis.

3. Tempo de duração: 60 minutos.

4. Material necessário: lousa e giz

5. Sugestões para encaminhamento da oficina

O facilitador pergunta para todos os participantes quais doenças sexualmente transmissíveis conhecem, além da AIDS, e seus sinais (o que se pode observar) e sintomas (o que a pessoa sente). Anota no quadro todos os sinais e sintomas observados pelos participantes do grupo. Encerra-se a oficina com uma rodada de comentários e, se necessário, listagem de questões para aprofundamento do tema.

6. Texto de apoio

As DST são causadas por vários tipos de agentes. São transmitidas, principalmente, por contato sexual sem uso da camisinha com uma pessoa que esteja 
infectada. Geralmente manifestam-se por meio de sinais como feridas, corrimentos, bolhas ou verrugas.

Atualmente, a suspeita de uma DST é feita a partir de uma abordagem chamada sindrômica, isto é, que leva em conta a presença de um ou mais sintomas (como coceira, verrugas, ardor ao urinar, feridas, dor na parte baixa da barriga, corrimento etc.). Todas as DST têm tratamento e, com exceção da AIDS, todas têm cura, mas precisam ser tratadas com medicamentos de tipos diferentes. Por isso o uso de medicamentos comprados na farmácia, embora seja um hábito comum, muitas vezes apenas para mascarar os sintomas dessas doenças, dificultando o diagnóstico e o tratamento. Algumas DST, quando não diagnosticadas e tratadas a tempo, podem evoluir para complicações graves e até para a morte.

Algumas DST são de fácil tratamento e de rápida resolução. Outras, contudo, tem tratamento mais difícil ou podem persistir ativas, apesar da sensação de melhora dos sintomas iniciais. As mulheres, em especial, devem ser bastante cuidadosas, já que, em diversos casos de DST, não é fácil distinguir os sintomas das reações orgânicas comuns de seu organismo. É importante ressaltar que algumas DST também podem ser transmitidas da mãe para o bebê, durante a gravidez ou na hora do parto. Podem provocar a interrupção espontânea da gravidez ou causar lesões ao feto. Outras DST podem ser transmitidas por transfusão de sangue contaminado, ou compartilhamento de seringas ou agulhas.

O tratamento tem como principal objetivo interromper a cadeia de transmissão da doença. O atendimento e o tratamento de DST são gratuitos nos serviços de saúde do SUS. As DST são o principal fator facilitador da transmissão sexual do vírus da AIDS, pois feridas nos órgãos genitais favorecem a entrada do HIV. O uso de preservativos em todas as relações sexuais é o método mais eficaz para a redução do risco de transmissão, tanto das DST quanto do vírus da AIDS.

\section{Dinâmicas}

TÉCNICAS DE PREVENÇÃO ÀS DST/AIDS

Não sei cuidar da minha vida

Objetivo: refletir sobre auto-cuidado, vulnerabilidade individual.

Duração: 40 minutos

Material: quadro "quem faz isso"

\begin{tabular}{|c|l|}
\hline Opções & Quem \\
\hline 1 & Homem \\
\hline 2 & Mulher \\
\hline 3 & Os dois \\
\hline 4 & Nenhum dos dois \\
\hline
\end{tabular}

\begin{tabular}{|l|c|}
\hline \multicolumn{1}{|c|}{ Faz isso } & Opções \\
\hline Vai ao médico regularmente & \\
\hline Vai ao médico quando sente alguma diferença no corpo & \\
\hline Compra camisinha & \\
\hline Traz a camisinha consigo & \\
\hline Coloca a camisinha & \\
\hline $\begin{array}{l}\text { Conversa com os amigos, com a família, com os professores e com } \\
\text { os adultos. }\end{array}$ & \\
\hline Negocia o uso da camisinha com seu parceiro ou parceira & \\
\hline Busca informações & \\
\hline Conhece 5 funcionamentos dos aparelhos reprodutivos masculino e & \\
\hline
\end{tabular}




\begin{tabular}{|l|l|}
\hline feminino & \\
\hline Conhece os métodos contraceptivos & \\
\hline Escolhe o método & \\
\hline Usa o método & \\
\hline
\end{tabular}

Desenvolvimento

1. O subgrupo discutirá a lista, colocando na frente de cada afirmativa o que, na opinião deles, só o homem faz só a mulher faz, nenhum dos dois fazem ou o que os dois fazem. Esse trabalho final, que deverá ser escrito em papel pardo, será discutido com o grupão.

2. O que os garotos e as garotas gostam de fazer para conquistar quem eles gostam?

3. O subgrupo discutirá o tema dentro da sua experiências e construirão duas listas uma para os garotos e outra para as garotas. Escreverá os itens dessas listas em papel pardo, numerando-os. Depois analisará, item por item, para ver se existe risco. Se existir, ele deverá ser escrito ao lado do item, ou com a sua numeração. Este trabalho final será discutido com o grupão.

Sugestão para reflexão: O facilitador, após as representações dos subgrupos, ressaltará as idéias mais importantes para discutir a vulnerabilidade, procurando fazer o grupo refleti sobre as condutas que fragilizam os jovens, sobre os recursos individuais, institucionais e sociais da localidade com os quais podem contar para se protegerem. Levá-los ainda a refletir sobre a possibilidade de efetuar mudanças em si próprias, para que se tornem menos vulneráveis, e a propor, também, mudanças ou novas formas de se dar atenção aos jovens de sua localidade com o mesmo propósito, prevenindo-se os agravos e promovendo a saúde integral.

(FONTE - Álbum Seriado - "Adolescência/Vulnerabilidade - GTPOS)

8. Atividade de Incentivo à leitura

Para buscar um maior esclarecimento e incentivar os alunos à leitura será distribuído em sala de aula nas turmas de EJA cartilhas informativas sobre amor próprio e DST/AIDS. No $1^{\circ}$ momento haverá uma leitura compartilhada, logo após os alunos debaterão sobre o texto lido. No $2^{\circ}$ momento os alunos responderão questionário sobre o tema e compartilharão suas conclusões com toda sala. Ao final da atividade de incentivo à leitura os mesmos produzirão textos expondo sua opinião sobre o tema tratado.

\section{CRONOGRAMA}

\begin{tabular}{|l|l|l|l|l|l|l|l|l|l|l|l|l|}
\hline AÇÕES & JAN & FEV & MAR & ABR & MAI & JUN & JUL & AGO & SES & OUT & NOV & DEZ \\
\hline Elaboração & & $\mathrm{X}$ & $\mathrm{X}$ & $\mathrm{X}$ & $\mathrm{X}$ & & & & & & & \\
\hline Reuniões & & $\mathrm{X}$ & $\mathrm{X}$ & $\mathrm{X}$ & $\mathrm{X}$ & & & & & & & \\
\hline Execução & & & & $\mathrm{X}$ & $\mathrm{X}$ & $\mathrm{X}$ & $\mathrm{X}$ & & & & & \\
\hline Avaliação & & & & & & & $\mathrm{X}$ & $\mathrm{X}$ & $\mathrm{X}$ & $\mathrm{X}$ & $\mathrm{X}$ & $\mathrm{X}$ \\
\hline
\end{tabular}




\section{PARCEIROS}

Equipe de professores

Coordenação

Secretaria de Saúde do DF

SESC _ Serviço Social do Comercio

Secretaria de Educação do Município Cidade Ocidental

\section{ORÇAMENTO}

No custeio desse projeto, utilizamos recursos, como revista em quadrinhos informativa sobre as DST tiragem de 3000 exemplares; três próteses do órgão reprodutor masculino e um feminino; 1000 preservativos. Todos os custos com material didático, as próteses e a revista informativa, foram onerados pelo SESC, um de nossos parceiros e os preservativos pela Secretaria de Saúde do DF.

\section{ACOMPANHAMENTO E AVALIAÇÃO}

A avaliação se dará:

- Avaliação de processo - examinar os diversos procedimentos e atividades e eficiência das atividades, enfatizando os resultados mais imediatos.

- Avaliação de resultados - buscar informações de natureza quantitativa ou qualitativa, buscando dados descritivos sobre o projeto, ou seja, o produto das atividades desenvolvidas. Exemplo: maior uso de preservativos após a realização de palestras, oficinas, distribuições de folhetos, cartilhas.

- Avaliação de impacto - realizada através de entrevistas com questionários auto-aplicativos.

E ainda:

$\checkmark$ Avaliar a utilização dos materiais didáticos específicos, para apoio ao trabalho dos professores;

$\checkmark$ Avaliar a utilização do espaço pedagógico e interdisciplinar das reuniões pedagógicas, para o envolvimento dos professores, de todos os componentes curriculares, no desenvolvimento de uma educação centrada em valores. 
$\checkmark$ Avaliar o grau de envolvimento todos os pais nas ações educativas de prevenção.

\section{REFERÊNCIAS}

ALTMANN, H. Orientação Sexual nos Parâmetros Curriculares Nacionais. Revista Estudos Feministas, ano 9, 2002.

FREIRE, Paulo. A Importância do Ato de ler - em três artigos que se completam. 11ํㅡ. São Paulo, Cortez, 1985.

MOTTA, A.; PORTO, H. R. L. As cidades são o palco. Democracia Viva, v. 03, 1995.

NUNES, Cezar, SILVA, Edna. A educação sexual da criança. São Paulo, editora 21 autores associados, 2000.

SOUZA, Hália Pauliv de. Convivendo com seu sexo (Pais e Professores). 2 ed. São Paulo: Paulinas, 1991.

SAMPAIO, Simaia. Educação sexual para além dos tabus. Salvador, UFBA, 1996.

VYGOSTSKY, Lev S. Pensamento e Linguagem. São Paulo, Martins Fontes, 1984. 
